\title{
The pigment complex of Sanguisorba officinalis L. in the native flora of Kemerovo Oblast
}

\author{
Natalia Yegorova*, Irina Yegorova \\ Federal Research Center of Coal and Coal Chemistry of SB RAS, 10, Leningradsky Avenue, \\ Kemerovo, 650065, Russia
}

\begin{abstract}
The paper is devoted to studying the content of photosynthetic pigments of Sanguisorba officinalis L. leaves at different vegetative growth stages. Plants were obtained from several habitats (a flood forbdominated meadow, a dry forb-dominated meadow, a birch forest). In the course of the research it was discovered that the concentration of the sum total of chlorophylls and carotenoids in great burnet leaves varied from the minimum values in May $(2.58-2.82 \mathrm{mg} / \mathrm{g})$ to the maximum values in July $(3.07-3.70 \mathrm{mg} / \mathrm{g})$ with a subsequent decrease in September $(2.49-$ $3.08 \mathrm{mg} / \mathrm{g}$ ). Moreover, the light intensity and moistening of the habitat also have an effect on photosynthetic pigment content.
\end{abstract}

\section{Introduction}

Kemerovo Oblast - Kuzbass is notorious for its severe anthropogenic impact on the environment. The chemical and metallurgical industries in the area are well-developed, and in combination with open-pit coal production increase they pollute the nature in the region (i.e. water, air, soil). Another negative influence is a decrease in the native habitat area of many valuable plants, including medicinal herbs.

The growing anthropogenic pressure has a detrimental effect on plant bodies as they have to adapt to changing external conditions in the process of their vital activity. One of plant adaptive responses is the functioning of their photosynthetic pigment apparatus, namely the qualitative and quantitative composition of the pigment system.

Many researchers believe that it is the pigment content that is indicative of the general condition of plant bodies [1,2].

Relevant literature mostly deals with tree vegetation, studying its pigment system condition, the dynamics and the ratio of its components. As for herbaceous vegetation, particularly medicinal, it is still an understudied area [3, 4]. Consequently, the question of chlorophyll and carotenoid participation in the adaptive mechanisms of medicinal plants especially in territories characterised by high levels of anthropogenic impact in native habitat conditions is still relevant.

\footnotetext{
${ }^{*}$ Corresponding author: nir kem@mail.ru
} 
The aim of this study was to determine photosynthetic pigment content (chlorophyll a, chlorophyll b, and carotenoids) in the leaves of Sanguisorba officinalis L. growing in Kemerovo Oblast - Kuzbass.

\section{Materials and methods}

The research objects were great burnet leaves (Sanguisorba officinalis L.). This is a valuable medicinal herb which has found widespread application in both conventional and traditional medicine. Great burnet grows throughout Kemerovo Oblast and often forms quite big tangles [5].

Three observation plots (OP) were chosen in Topkinsky district. OP1 was a flood forbdominated meadow located $15.5 \mathrm{~km}$ to the south-west of Kemerovo. Light intensity in the meadow is high during the day. Great burnet grows abundantly. The plot soil is groundwater and atmospherically moistened. According to its granulometric composition, the soil on the plot is a heavy clay loam. The soil $\mathrm{pH}$ is close to neutral - 5.6; the humus content is $7.3 \%$; the mass concentration of labile phosphorus compounds is elevated -106 $\mathrm{mg} / \mathrm{kg}$; the mass concentration of labile potassium compounds is extremely elevated -340 $\mathrm{mg} / \mathrm{kg}$. OP2 was a dry forb-dominated meadow located $17 \mathrm{~km}$ from Kemerovo on the eastern slope of a hill. The slope gradient is about $40^{\circ}$. Great burnet grows abundantly. This slope is open, with no bushes; therefore, its light intensity is high. The soil on the plot is atmospherically moistened and classified as a heavy clay loam. The soil $\mathrm{pH}$ is close to neutral -5.8 ; the humus content is $6.2 \%$; the content of labile phosphorus is elevated -114 $\mathrm{mg} / \mathrm{kg}$; the content of exchangeable potassium is extremely elevated $-345 \mathrm{mg} / \mathrm{kg}$. OP3 is a birch forest located in the vicinity of St. Topki village within the territory of Topkinsky forest district. The crown closure on the plot is 0.3 . The underbrush is poor. Great burnet grows sporadically in open spots in rather high grass canopy. The plot soil is atmospherically moistened. According to its granulometric composition, the soil on the plot is a heavy clay loam. The soil $\mathrm{pH}$ is close to neutral -5.6 ; the humus content is $5.6 \%$; the content of labile phosphorus compounds is average - $73 \mathrm{mg} / \mathrm{kg}$; the exchangeable potassium content is high $-180 \mathrm{mg} / \mathrm{kg}$.

The weather conditions in the year of the research were generally typical for this area (Table 1):

Table 1. Weather conditions throughout the research period

\begin{tabular}{|l|c|c|c|c|c|c|c|c|c|c|}
\hline Conditions & \multicolumn{2}{|c|}{ May } & \multicolumn{2}{c|}{ June } & \multicolumn{2}{c|}{ July } & \multicolumn{2}{c|}{ August } & \multicolumn{2}{c|}{ September } \\
\hline $\begin{array}{l}\text { Mean average } \\
\text { temperature, }\end{array}$ & 1 & 2 & 1 & 2 & 1 & 2 & 1 & 2 & 1 & 2 \\
\cline { 2 - 11 } & 11.2 & 10.1 & 16.4 & 16.1 & 19.0 & 18.6 & 16.2 & 18.6 & 9.6 & 10.4 \\
\hline $\begin{array}{l}\text { Amount of } \\
\text { precipitation, } \\
\text { mm }\end{array}$ & 40 & 39 & 68 & 55 & 72 & 70 & 62 & 64 & 41 & 61 \\
\hline
\end{tabular}

Note: 1- the norm; 2- actual

The great burnet leaves for the investigation were collected at different seasonal development phenophases in 2019: the leaf expansion stage (LES - May), the budding stage (BS - June), the flowering stage (FS - July), and fruiting stage (FrS - September). Leaf samples were taken from $3-5$ plants at $11-12$ am (local time). The samples were then placed into lightproof plastic bags with ice and transported to the laboratory. Tests were performed on the same day.

Pigments were extracted with $80 \%$ ethanol. The absorbency of the extract was determined using a LEKI SS 1207 spectrophotometer. Three biological replicates were 
analysed. The pigment presence was calculated in $\mathrm{mg} / \mathrm{g}$ of fresh weight by the methods of Mac-Kinny and Wettstein [6]. The statistical analysis was performed with the Statistica 6.1 and Microsoft Office Excel 2007 software packages. The critical value of statistical significance level was taken to be equal 0.05

\section{Results and discussion}

The study of seasonal pigment dynamics in great burnet leaves from May to September 2019 showed that chlorophyll and carotenoid (car.) content changes throughout the entire vegetation period. What is more, the quantity of both chlorophyll a (chl. a) and chlorophyll b (chl. b) reached a maximum in July on all three observation plots (Table 2).

Table 2. Seasonal dynamics of pigment content ( $\mathrm{mg} / \mathrm{g}$ of fresh weight) and pigment ratio in the leaves of Sanguisorba officinalis L. on observation plots (average data for 2019)

\begin{tabular}{|c|c|c|c|c|c|c|}
\hline \multirow{2}{*}{$\begin{array}{c}\text { Vegetative } \\
\text { phase }\end{array}$} & \multicolumn{7}{c|}{ Identifiable indicators } \\
\cline { 2 - 7 } & chl. a & chl. b & car. & $\begin{array}{c}\text { chl. a+chl. } \\
\text { b }\end{array}$ & $\begin{array}{c}\text { chl. a /chl. } \\
\text { b }\end{array}$ & $\begin{array}{c}\text { chl. a }+ \text { chl. } \\
\text { b/car. }\end{array}$ \\
\hline \multicolumn{7}{|c|}{ OP1 - flood forb-dominated meadow } \\
\hline LES & $1.36 \pm 0.01$ & $0.80 \pm 0.01$ & $0.81 \pm 0.01$ & $2.12 \pm 0.01$ & $1.20 \pm 0.01$ & $2.66 \pm 0.01$ \\
\hline BS & $1.77 \pm 0.02$ & $0.74 \pm 0.02$ & $0.86 \pm 0.01$ & $2.51 \pm 0.04$ & $2.38 \pm 0.02$ & $2.93 \pm 0.02$ \\
\hline FS & $1.89 \pm 0.01$ & $0.82 \pm 0.01$ & $0.88 \pm 0.06$ & $2.70 \pm 0.01$ & $2.35 \pm 0.01$ & $3.07 \pm 0.01$ \\
\hline FrS & $1.50 \pm 0.01$ & $0.64 \pm 0.07$ & $0.86 \pm 0.02$ & $2.14 \pm 0.06$ & $2.40 \pm 0.02$ & $2.49 \pm 0.01$ \\
\hline \multicolumn{7}{|c|}{ OP2 - dry forb-dominated meadow } \\
\hline LES & $1.48 \pm 0.01$ & $0.57 \pm 0.01$ & $0.73 \pm 0.01$ & $2.04 \pm 0.01$ & $2.60 \pm 0.02$ & $2.82 \pm 0.01$ \\
\hline BS & $1.77 \pm 0.02$ & $0.79 \pm 0.01$ & $0.84 \pm 0.02$ & $2.56 \pm 0.01$ & $2.24 \pm 0.01$ & $3.04 \pm 0.01$ \\
\hline FS & $1.99 \pm 0.03$ & $0.85 \pm 0.02$ & $0.87 \pm 0.01$ & $2.83 \pm 0.01$ & $2.35 \pm 0.01$ & $3.25 \pm 0.01$ \\
\hline FrS & $1.83 \pm 0.01$ & $0.77 \pm 0.01$ & $0.85 \pm 0.01$ & $2.60 \pm 0.01$ & $2.37 \pm 0.04$ & $3.08 \pm 0.01$ \\
\hline \multicolumn{7}{|c|}{ OP3- birch forest } \\
\hline LES & $1.52 \pm 0.02$ & $0.58 \pm 0.02$ & $0.82 \pm 0.01$ & $2.10 \pm 0.03$ & $2.63 \pm 0.04$ & $2.58 \pm 0.03$ \\
\hline BS & $1.60 \pm 0.02$ & $0.71 \pm 0.01$ & $0.82 \pm 0.01$ & $2.32 \pm 0.01$ & $2.25 \pm 0.01$ & $2.88 \pm 0.04$ \\
\hline FS & $2.12 \pm 0.01$ & $1.21 \pm 0.01$ & $0.90 \pm 0.03$ & $3.34 \pm 0.01$ & $1.75 \pm 0.01$ & $3.70 \pm 0.01$ \\
\hline FrS & $1.61 \pm 0.03$ & $0.67 \pm 0.01$ & $0.80 \pm 0.01$ & $2.28 \pm 0.01$ & $2.41 \pm 0.02$ & $2.84 \pm 0.02$ \\
\hline
\end{tabular}

Carotenoids are an obligatory component of the pigment system. The study of their quantity in great burnet leaves revealed that carotenoid content is a rather dynamic characteristic. Carotenoids gradually accumulate in great burnet leaves, and the maximum content of carotenoids is also observed in July (Table 2). On OP1 the content was 0.88 $\mathrm{mg} / \mathrm{g}$, on OP $2-0.87 \mathrm{mg} / \mathrm{g}$, and on OP $3-0.90 \mathrm{mg} / \mathrm{g}$ (Table 2). This is probably due to the protective function of carotenoid pigments: they safeguard chlorophylls from excessive solar radiation. In July there were more sunny and warm days than in the other months of the 2019 summer season (Table 1).

The data provided in Table 2 indicates similarities of the quantitative characteristics and reveals seasonal patterns of pigment accumulation. It was found that great burnet leaves contained 2.9 times more green pigments than yellow pigments. In addition, the reduction in pigment content in the autumn period is in the first place connected with the structural and functional plant changes. Plants at this time of year prepare for the dormant period and the death of their aboveground parts.

The comparative analysis of photosynthetic pigment concentrations in great burnet leaves identified several (though not very significant) differences on the plots under observation. These dissimilarities can be most likely accounted for by the changes in the 
growth conditions. During the flowering stage in July shadowing on OP3 intensified, whereas on OP1 and OP2 solar irradiance increased. Besides, pigment concentration depends on moistening: in dry places (OP2) it is lower than on OP1.

Another important indicator which is necessary to estimate the maturity of photosynthetic apparatus is the chl. a/chl. b ratio. It is believed that the higher the value is, the more enhanced the photosynthesis process becomes. In normal conditions the value of the ratio should vary between 2.2-3.0. During the undertaken research the ratio of chl.a to chl.b ranged from 1.20 to 2.81 on OP1, on OP2 - from 1.66 to 2.73 , and on OP3 - from 1.38 to 2.63 (Table 2). Thus, it can be said that great burnet has adapted successfully to the existing growth conditions.

Besides, it was of interest to analyse another indicator, namely the ratio of the sum total of chlorophylls to carotenoids (chl. a+chl. b/car.) as this ratio also characterises the functioning of the photosynthetic apparatus. This indicator is stable in favourable conditions, but at the same time it is sensitive to the changes of habitat factors. In terms of this indicator, the obtained data is fairly stable (Table 2). A trend towards a decrease in the chl.a+chl.b/car. ratio is observed at the end of summer and the beginning of autumn, which evidences a weakening of the light-harvesting function of the pigment complex in unfavourable temperature conditions (Table 2).

\section{Conclusion}

Therefore, the quantitative characteristics of the pigment complex in Sanguisorba officinalis L. leaves showed that the concentration of the sum total of chlorophylls and carotenoids varied from the minimum in May $(2.58-2.82 \mathrm{mg} / \mathrm{g})$ to the maximum values in July $(3.07-3.70 \mathrm{mg} / \mathrm{g})$ with a subsequent decrease in September $(2.49-3.08 \mathrm{mg} / \mathrm{g})$. In addition, light intensity and moistening in habitats also have an impact on pigment content.

The work was carried out within the framework of the state assignment of the Federal Research Center of Coal and Coal Chemistry SB RAS (project no. 0286-2021-0010).

\section{References}

1. T.G. Maslova, I.A. Popova, Photosynthetica, 29, 195-203 (1993)

2. A.T. Mokronosov, V.F. Gavrilenko, Photosynthesis: physiological and environmental aspects (Moscow University Press, Moscow, 1992)

3. O.L. Tsandekova, O.A. Neverova, Izvestia of the Samara Research Centre 12(33), 1(3), 853-857 (2020)

4. Ye.A. Karpova, T.D. Fershalova, Tomsk State University Journal of Biology 1(33), 140-158 (2016)

5. I.N. Yegorova, Content of heavy metals and radionuclides in raw medicinal herbs of the Kemerovo region, Candidate of Biological Sciences Dissertation, Tomsk (2010)

6. V.F. Gavrilenko, T.V. Zhigalova, A large practicum on photosynthesis (Moscow, 2003) 